\title{
Crop Recommendation System using Machine Learning
}

\section{Dhruvi Gosai ${ }^{1}$, Chintal Raval ${ }^{2}$, Rikin Nayak ${ }^{3}$, Hardik Jayswal ${ }^{4}$, Axat Patel ${ }^{5}$}

1,2,4Charotar University of Science and Technology, Devang Patel Institute of advance Technology and Research, Changa, Department of Computer Engineering, Ta-Petlad, Anand, Gujarat, India.

${ }^{3}$ Charotar University of Science and Technology, CHARUSAT Space Research and Technology Center,

V T Patel Department of E \& C Engineering, CSPIT, Changa, Ta-Petlad, Anand, Gujarat, India

${ }^{5}$ Charotar University of Science and Technology, CHARUSAT Space Research and Technology Center,

C M Department of Mechanical Engineering, CSPIT, Changa, Ta-Petlad, Anand, Gujarat, India

Article Info

Volume 7, Issue 3

Page Number: 554-557

Publication Issue :

May-June-2021

Article History

Accepted : 06 June 2021

Published : 13 June 2021

\section{ABSTRACT}

A vast fraction of the population of India considers agriculture as its primary occupation. The production of crops plays an important role in our country. Bad quality crop production is often due to either excessive use of fertilizer or using not enough fertilizer. The proposed system of IoT and ML is enabled for soil testing using the sensors, is based on measuring and observing soil parameters. This system lowers the probability of soil degradation and helps maintain crop health. Different sensors such as soil temperature, soil moisture, $\mathrm{pH}, \mathrm{NPK}$, are used in this system for monitoring temperature, humidity, soil moisture, and soil $\mathrm{pH}$ along with NPK nutrients of the soil respectively. The data sensed by these sensors is stored on the microcontroller and analyzed using machine learning algorithms like random forest based on which suggestions for the growth of the suitable crop are made. This project also has a methodology that focuses on using a convolutional neural network as a primary way of identifying if the plant is at risk of a disease or not.

Keywords : Soil nutrient identification, Crop suggestion, Plant pathology, Nitrogen-Phosphorus-Potassium (NPK), Internet of Things (IoT), Machine Learning (ML), Convolutional Neural Network (CNN), KNearest Neighbour (KNN).

Abbreviations : Decision Tree (DT), Naïve Bayes (NB), Support Vector Machine (SVM), Logistic Regression (LR), Random Forest (RF).

\section{INTRODUCTION}

Agriculture is a significant area for the Indian economy and human survival. It is one of the primary occupations which is essential for human life. It likewise contributes a huge part to our day-to-day life [1]. In most cases, Farmers commit suicide due to production loss because they are not able to pay the bank loans taking for farming purposes[12]. We have 
noticed in present times that the climate is changing persistently which is harmful to the crops and leading farmers towards debts and suicide [18]. These risks can be minimized when various mathematical or statistical methods are applied to data and by using these methods, we can recommend the best crop to the farmer for his Agricultural land so that it helps him to get maximum profit [12].

Nowadays agriculture has developed a lot in India. "site-specific" farming is the key to Precision agriculture. Although precision agriculture has achieved better enhancements it is still facing certain issues. Precision agriculture plays an important role in the recommendation of crops. The recommendation of crops is dependent on various parameters.

Precision agriculture focuses on identifying these parameters in a site-specific way to identify issues. Not all the results given by precision agriculture are accurate to result but in agriculture, it is significant to have accurate and precise recommendations because in case of errors it may lead to heavy material and capital loss. Many research works are being carried out, to attain an accurate and more efficient model for crop prediction [11].

Machine Learning focuses on the algorithm like supervised, unsupervised, and Reinforcement learning and each of them has its advantages and disadvantages. Supervised learning the algorithm assembles a mathematical model from a set of data that contains both the inputs and the desired outputs. An unsupervised learning-the algorithm constructs a mathematical model from a set of data that contains only inputs and no desired output labels. Semi-supervised learning- algorithms expand mathematical models from incomplete training data, where a portion of the sample input doesn't have labels [8].

This paper aims to recommend the most suitable crop based on input parameters like Nitrogen (N), Phosphorous (P), Potassium (K), $\mathrm{PH}$ value of soil, Humidity, Temperature, and Rainfall. This paper predicts the accuracy of the future production of eleven different crops such as rice, maize, chickpea, kidney beans, pigeon peas, moth beans, mungbean, black gram, lentil, pomegranate, banana, mango, grapes, watermelon, muskmelon, apple, orange, papaya, coconut, cotton, jute, and coffee crops using various supervised machine learning approaches in of India and recommends the most suitable crop. The dataset contains various parameters like Nitrogen (N), Phosphorous (P), Potassium (K), PH value of soil, Humidity, Temperature, and Rainfall. This proposed system applied different kinds of Machine Learning algorithms like Decision Trees, Naïve Bayes (NB), Support Vector Machine (SVM), Logistic Regression, Random Forest (RF), and XGBoost [12].

This paper can be divided into five different segments: Segment 1 presents Related work and Compartive study regarding crop recommendation system using machine learning approach. Segment 2 presents Proposed system approach. Segment 3 presents Experiemental Result Analysis and Segment 4 presents Conclusion and Future Work.

\section{RELATED WORK}

[1] Kumar, Y. Jeevan Nagendra, V. Spandana, V. S. Vaishnavi, K. Neha, and V. G. R. R. Devi. "Supervised Machine learning Approach for Crop Yield Prediction in Agriculture Sector". In this proposed system crop yield prediction can 
be done from the past historical data which includes factors such as temperature, humidity, ph, rainfall, crop name. Under this system, maximum types of crops will be covered across different districts of India. By applied this proposed system, we can predicted best crop according to the field weather conditions. This crop prediction can be done by random forest algorithm and decision tree. By applying random forest algorithm got best accurate value result. More accuracy results gave more profit to the crop yield.

[9] Suresh, G., A. Senthil Kumar, S. Lekashri, and R. Manikandan. "Efficient Crop Yield Recommendation System Using Machine Learning For Digital Farming". This proposed system is used to identify particular crop according to given particular data. By applying Support Vector Machine (SVM) acquired higher precision and productivity. This research paper mainly worked on two datasets: sample dataset of location data and sample dataset of crop data. By using this proposed system recommended particular crop according to their Nutrients $(\mathrm{N}$, $\mathrm{P}, \mathrm{K}$, and $\mathrm{PH}$ ) values and also identified available Nutrients values and required fertilizers quantities for the particular crop like Rice, Maize, Black gram, Carrot and Radish.

[10] Reddy, D. Anantha, Bhagyashri Dadore, and Aarti Watekar. "Crop recommendation system to maximize crop yield in ramtek region using machine learning". This proposed system worked on three parameters: soil characteristics, soil types and crop yield data collection based on these parameters suggesting the farmer suitable crop to be cultivated. This proposed system worked on different machine learning algorithms like random forest, CHAID, K-Nearest Neighbour and Naïve Bayes. By applied this proposed system we can predict particular crop under particular weather condition, state and district values. Thus our proposed work would help farmers in sowing the right seed based on soil requirements to increase productivity of the nation.

[14] Rajak, Rohit Kumar, Ankit Pawar, Mitalee Pendke, Pooja Shinde, Suresh Rathod, and Avinash Devare. "Crop recommendation system to maximize crop yield using machine learning technique". This proposed method is used for identifying particular crop based on soil database. This proposed system worked on various crops like groundnut, pulses, cotton, vegetables, banana, paddy, sorghum, sugarcane, coriander and various attributes like Depth, Texture, Ph, Soil Color, Permeability, Drainage, Water holding and Erosion. This proposed system worked on various machine learning classifier like support vector machine (SVM) classifier, ANN classifier, Random Forest and Naïve Bayes for recommend a crop for site specific parameter with accuracy and efficiency. This research work would help farmers to increase productivity in agriculture, prevent soil degradation in cultivated land, and reduce chemical use in crop production and efficient use of water resources.

[15] Doshi, Zeel, Subhash Nadkarni, Rashi Agrawal, and Neepa Shah. "AgroConsultant: Intelligent Crop Recommendation System Using Machine Learning Algorithms". In this research paper, developed an intelligent system called AgroConsultant. This proposed system can be divided into two sub-systems: i) crop suitable predictor ii) Rainfall Predictor. This proposed system are worked on five major (bajra, jowar, maize, rice and wheat) and fifteen minor (barley, cotton, groundnut, gram, jute, other pulses, potato, ragi, tur, rapeseed and mustard, sesame, 
soybean, sugarcane, sunflower, tobacco) crops and some attributes like Soil Type, Aquifer thickness, Soil PH, Thickness of topsoil, Precipitation, Temperature, Location parameters. In this proposed system Implemented different machine learning algorithms like Decision Tree, $\mathrm{K}$ Nearest Neighbor (K-NN), Random Forest and Neural Network and performed multi-label classification on it. This proposed system achieved $71 \%$ accuracy by using rainfall predictor model and achieved $91.00 \%$ accuracy by applying neural network algorithm on crop suitable predictor system.

[18] Dighe, Deepti, Harshada Joshi, Aishwarya Katkar, Sneha Patil, and Shrikant Kokate. "Survey of Crop Recommendation Systems". This proposed system developed a crop recommendation system for smart farming. In this research paper reviewed various machine learning algorithms like CHAID, KNN, K-means,
Decision Tree, Neural Network, Naïve Bayes, C4.5, LAD, IBK and SVM algorithms. For this research used Hadoop framework for the intensive calculations and also helped to get better accuracy for the system.

[21] Kulkarni, Nidhi H., G. N. Srinivasan, B. M. Sagar, and N. K. Cauvery. "Improving Crop Productivity Through A Crop Recommendation System Using Ensembling Technique". This proposed system is used for recommended the right crop based on the soil specific type and characteristics like average rainfall and the surface temperature with high accuracy. This proposed system worked on various machine learning algorithms like Random Forest, Naive Bayes, and Linear SVM. This crop recommendation system classified the input soil dataset into the recommendable crop type, Kharif and Rabi. By applying this proposed system achieved $99.91 \%$ accuracy result.

\section{COMPARATIVE STUDY}

\begin{tabular}{|c|c|c|c|c|c|}
\hline $\begin{array}{l}\text { Types of } \\
\text { crops }\end{array}$ & Attributes & Datasets & Methodology & Accuracy & $\begin{array}{l}\text { Referenc } \\
\text { es }\end{array}$ \\
\hline $\begin{array}{l}\text { Various } \\
\text { crops }\end{array}$ & $\begin{array}{l}\text { Temperatur } \\
\text { e Rainfall, } \\
\text { Humidity, } \\
\text { ph }\end{array}$ & $\begin{array}{c}\text { Kaggle } \\
\text { website }\end{array}$ & RF, DT & $\begin{array}{l}\text { RF give best } \\
\text { accuracy } \\
\text { result }\end{array}$ & [1] \\
\hline $\begin{array}{l}\text { Rice, Jowar } \\
\text { Wheat, } \\
\text { Soybeans } \\
\text { Sunflower, } \\
\text { Cotton, } \\
\text { Sugarcane } \\
\text { Tobacco } \\
\text { Onion, Dry } \\
\text { Chilli }\end{array}$ & $\begin{array}{l}\text { Soil } \\
\text { nutrients, } \\
\text { Location } \\
\text { data, } \\
\text { Weather } \\
\text { information, } \\
\text { Temperatur } \\
\text { e, Humidity, } \\
\text { Atmospheric } \\
\text { Pressure }\end{array}$ & $\begin{array}{c}\text { Online } \\
\text { sources }\end{array}$ & SVM, RF & $\begin{array}{l}\mathrm{SVM}=99.47 \% \\
\mathrm{RF}=97.48 \%\end{array}$ & [8] \\
\hline $\begin{array}{l}\text { Groundnut, } \\
\text { Pulses, Cotton, } \\
\text { Vegetables, } \\
\text { Paddy, }\end{array}$ & $\begin{array}{l}\text { Soil } \\
\text { characteristi } \\
\text { cs Soil types, } \\
\text { Weather }\end{array}$ & $\begin{array}{l}\text { Nagpur, } \\
\text { Maharashtr } \\
\text { a, India }\end{array}$ & $\begin{array}{l}\text { RF, CHAID, } \\
\text { KNN, NB }\end{array}$ & $\begin{array}{l}\text { RF give best } \\
\text { accuracy } \\
\text { result }\end{array}$ & [10] \\
\hline
\end{tabular}




\begin{tabular}{|c|c|c|c|c|c|}
\hline $\begin{array}{l}\text { Sugarcane, } \\
\text { Coriander }\end{array}$ & & & & & \\
\hline $\begin{array}{l}\text { Millet,Ground } \\
\text { nutPulses, } \\
\text { Cotton, } \\
\text { Vegetables, } \\
\text { Banana, Paddy, } \\
\text { Sorghum, } \\
\text { Sugarcane, } \\
\text { Coriander }\end{array}$ & $\begin{array}{l}\text { Soil } \\
\text { characteristi } \\
\text { cs, Soil } \\
\text { types }\end{array}$ & $\begin{array}{l}\text { Madurai, } \\
\text { Tamil } \\
\text { Nadu, } \\
\text { India }\end{array}$ & $\begin{array}{l}\text { RF, CHAID, } \\
\text { KNN, NB }\end{array}$ & $\mathrm{RF}=88 \%$ & [11] \\
\hline $\begin{array}{l}\text { Rice, Ragi, } \\
\text { Gram, Potato, } \\
\text { Onion }\end{array}$ & $\begin{array}{l}\text { Precipitatio } \\
\text { n, Cloud } \\
\text { Cover, Area, } \\
\text { Pressure, } \\
\text { Season }\end{array}$ & $\begin{array}{l}\text { Andhra } \\
\text { Pradesh }\end{array}$ & RF, LR, DT,SVM & $\mathrm{MV}=94.78 \%$ & [12] \\
\hline $\begin{array}{l}\text { Groundnut, } \\
\text { pulses, Cotton, } \\
\text { Vegetables, } \\
\text { Banana, Paddy, } \\
\text { Sorghum, } \\
\text { Sugarcane, } \\
\text { Coriander }\end{array}$ & $\begin{array}{l}\text { Depth, } \\
\text { Texture, Ph, } \\
\text { Soil Color, } \\
\text { Permeability } \\
\text {, Drainage, } \\
\text { Water } \\
\text { holding and } \\
\text { Erosion }\end{array}$ & $\begin{array}{l}\text { Pune, } \\
\text { Maharashtr } \\
\text { a, India }\end{array}$ & $\begin{array}{l}\text { SVM, NB, ANN, } \\
\text { RF }\end{array}$ & $\begin{array}{l}\text { RF gives the } \\
\text { best accuracy } \\
\text { result }\end{array}$ & [14] \\
\hline $\begin{array}{l}\text { Bajra, Jowar, } \\
\text { Maize, Rice, } \\
\text { Wheat, Barley, } \\
\text { Cotton, } \\
\text { Groundnut, } \\
\text { Gram, Jute, } \\
\text { Potato, Ragi, } \\
\text { Tur, Rapeseed, } \\
\text { Mustard, } \\
\text { Sesame, } \\
\text { Soybean, } \\
\text { Sugarcane, } \\
\text { Sunflower, } \\
\text { Tobacco }\end{array}$ & $\begin{array}{l}\text { Season, } \\
\text { Geographica } \\
\text { l location, } \\
\text { Soil } \\
\text { characteristi } \\
\text { cs, } \\
\text { Temperatur } \\
\text { e, } \\
\text { Rainfall }\end{array}$ & $\begin{array}{l}\text { Data } \\
\text { contains } \\
\text { from } 13 \\
\text { major state } \\
\text { of India }\end{array}$ & $\begin{array}{lll}\text { DT, } & \text { KNN, RF, } \\
\text { NN } & \end{array}$ & $\begin{array}{l}\mathrm{DT}=90.20 \% \\
\mathrm{KNN}=89.78 \% \\
\mathrm{R}=90.43 \% \\
\mathrm{NN}=91.00 \%\end{array}$ & [15] \\
\hline $\begin{array}{l}\text { Millet, } \\
\text { Groundnut, } \\
\text { Pulses, Cotton, } \\
\text { Vegetables, } \\
\text { Banana, Paddy, } \\
\text { Sorghum, } \\
\text { Sugarcane, } \\
\text { Coriander }\end{array}$ & $\begin{array}{l}\text { Soil } \\
\text { Characteristi } \\
\text { csSoil types, } \\
\text { crop yield } \\
\text { data } \\
\text { collection }\end{array}$ & $\begin{array}{c}\text { Online } \\
\text { Sources }\end{array}$ & RT, KNN, NB & $\begin{array}{l}\text { RT gives the } \\
\text { best accuracy } \\
\text { result }\end{array}$ & [17] \\
\hline $\begin{array}{l}\text { Various } \\
\text { Crops }\end{array}$ & $\begin{array}{l}\text { Seasonal, } \\
\text { Soil, } \\
\text { Weather, }\end{array}$ & $\begin{array}{l}\text { Database } \\
\text { Server }\end{array}$ & $\begin{array}{l}\text { CHAID, KNN, K- } \\
\text { means, DT, NN, } \\
\text { NB, C4.5, LAD, }\end{array}$ & $\begin{array}{l}\text { SVM gives the } \\
\text { best accuracy } \\
\text { result }\end{array}$ & [18] \\
\hline
\end{tabular}




\begin{tabular}{|c|c|c|c|c|c|}
\hline & $\begin{array}{l}\text { Temperatur } \\
\text { e, } \\
\text { Topographic } \\
\text { al, Crop } \\
\text { Production, } \\
\text { and } \\
\text { economic } \\
\text { condition }\end{array}$ & & IBK, SVM & & \\
\hline $\begin{array}{l}\text { Cotton, } \\
\text { Sugarcane, } \\
\text { Rice, Wheat }\end{array}$ & $\begin{array}{l}\text { Soil Type, } \\
\text { pH value, } \\
\text { NPK value, } \\
\text { Rainfall, } \\
\text { Temperatur } \\
\text { e, } \\
\text { Sowing } \\
\text { season }\end{array}$ & $\begin{array}{l}\text { Governme } \\
\text { nt of India } \\
\text { (data.gov.i } \\
\text { n) }\end{array}$ & $\begin{array}{l}\text { RF, NB, Linear } \\
\text { SVM }\end{array}$ & $\begin{array}{l}\text { The average } \\
\text { accuracy of } \\
\text { crop } \\
\text { classification } \\
\text { into Kharif } \\
\text { and } \\
\text { crops Rabi } \\
99.91 \% \text {. }\end{array}$ & [21] \\
\hline
\end{tabular}

\section{Proposed System}

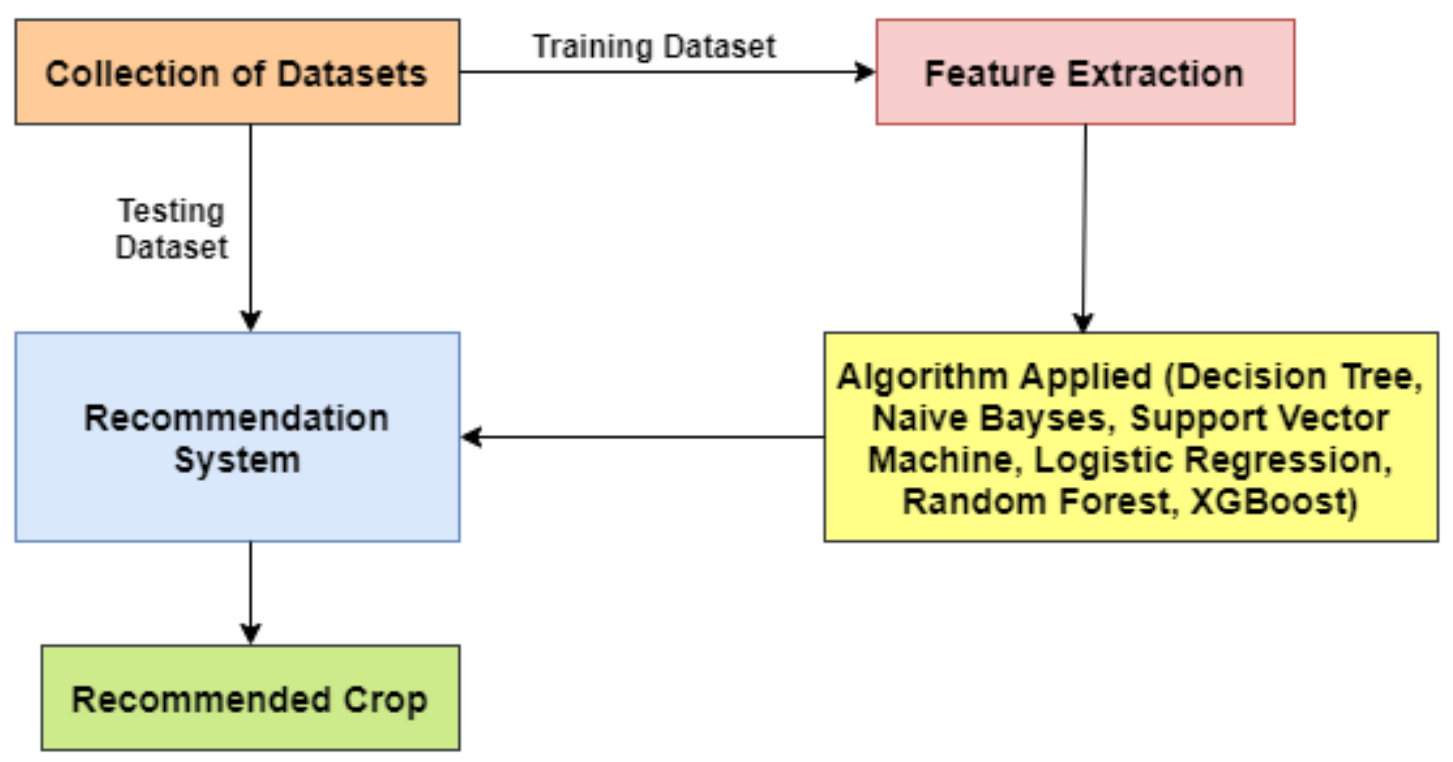

Fig 1 : Block Diagram of Overall Methodology of Proposed System

In our framework, we have proposed a procedure that is separated into various stages as appeared in Figure 1.

The five phases are as per the following:

1) Collection of Datasets
2) Pre-processing (Noise Removal)

3) Feature Extraction

4) Applied Various Machine Learning Algorithm

5) Recommendation System

6) Recommended Crop 


\section{Flow of the Proposed System}

As demonstrated in the figure, the methodology to extract the sentiment contains the several steps that are described below:

\section{(1) Data Collection:}

The dataset consists of parameters like Nitrogen(N), Phosphorous(P), Pottasium(K), PH value of soil, Humidity, Temperature and Rainfall. The datasets have been obtained from the Kaggle website. The data set has 2200 instance or data that have taken from the past historic data. This dataset include eleven different crops such as rice, maize, chickpea, kidneybeans, pigeonpeas, mothbeans, mungbean, blackgram, lentil, pomegranate, banana, mango, grapes, watermelon, muskmelon, apple, orange, papaya, coconut, cotton, jute, and coffee.

\section{(2) Pre-Processing (Noise Removal):}

For the successful application pre-processing is required. The data which is acquired from different resources are sometime in raw form. It may contain some incomplete, redundant, inconsistent data. Therefore in this step such redundant data should be filtered. Data should be normalized [5].

\section{(3) Feature Extraction:}

This step is focus on identifying and using most relevant attribute from the dataset. Through this process irrelevant and redundant information is removed for the application of classifiers [5].

\section{(4) Methodology:}

In this proposed system applied different Machine Learning algorithms like Decision Tree, Naïve Bayse (NB), Support Vector Machine (SVM), Logistic Regression (LR), Random Forest (RF) and XGBoost.

\section{A. Decision Tree:}

Decision tree classifiers utilize greedy methodology. It is a supervised learning algorithm where attributes and class labels are represented using a tree [15]. The main purpose of using Decision Tree is to form a training prototype which we can use to foresee class or value of target variables by learning decision rules deduced from previous data (training data). The Decision tree can be described by two distinct types, namely decision nodes and leaves. The leaves are the results or the final end results. Each node in the tree acts as a test case for some attribute, and each edge descending from that node corresponds to one of the possible answers to the test case. This process is recursive in nature and is repeated for every sub-tree rooted at the new nodes [22]. We have applied Decision tree approach in our model as:

(i) Importing library DecisionTreeClassifier from sklearn.tree Class

(ii) Now we create DecisionTree Classifier object

(iii) In the last we fit our data

\section{\# Decision Tree}

from sklearn.tree import DecisionTreeClassifier DecisionTree $=$ DecisionTreeClassifier $($ criterion ="entropy", random_state=2, max_depth=5)

DecisionTree.fit(Xtrain,Ytrain) 
Naive Bayes is an order calculation for binary and multi-class arrangement issues. At the point when binary or categorically input esteems are given, Naive Bayes strategy is exceptionally straightforward. In Naive Bayes, a Naive Bayes classifier accepts that the presence of a specific component in a class isn't at all identified with the presence of some other element. The Naive Bayes classifier relies upon the Bayes theory and this procedure is helpful in the situations where the dimensionality of the wellsprings of data is high. Naive Bayes has different applications, for example, for making predictions in real time, to predict the probability of multiple classes of target attribute, spam filtering, and coupled with collaborative filtering helps to build recommendation systems. At first the probability of each attribute in the dataset is to be determined which is otherwise called class probability. The conditional probability gives the conditional probability of each information value given each class value [21].

We have applied Naïve Bayes (NB) approach in our model as:

(i) Importing library GaussianNB Classifier from sklearn.naive_bayes Class

(ii) Now we create Naïve Bayes Classifier object

(iii) In the last we fit our data

\section{\# Naive Bayses (NB)}

from sklearn.naive_bayes import GaussianNB

NaiveBayes $=$ GaussianNB()

NaiveBayes.fit(Xtrain, Ytrain)

\section{Support Vector Machine (SVM):}

Support Vector Machine (SVM) is a supervised machine learning algorithm or model which can be utilized for classification and as well as for regression challenges. However, we mainly use it in classification challenges. SVM is generally represented as training data points in space which is divided into groups by intelligible gap which is as far as possible [22]. In SVM algorithm, each data item is plotted as a point in n-dimensional space with each feature value being the value of a specific coordinate. Then the classification is performed by finding the hyper-plane differentiating the two classes very well [19].

We have applied Support Vector Machine (SVM) approach in our model as:

(i) Importing library SVC from sklearn.svm Class

(ii) Now we create SVM classification object

(iii) At last we fit our data

\# Support Vector Machine(SVM)

from sklearn.svm import SVC

SVM = SVC(gamma='auto')

SVM.fit(Xtrain, Ytrain)

\section{Logistic Regression (LR)}

The Logistic Regression model is a broadly used statistical model that, in its basic form, uses a logistic function to model a binary dependent variable; many more complex extensions exist. In Regression Examination, Logistic regression is predicting the parameters of a logistic model; it is a form of Binomial regression [22].

We have applied Logistic Regression (LR) in our model as:

(i) Importing library LogisticRegression from sklearn.linear Class

(ii) Now we create LogReg classifier object

(iii) In the last we fit our data

\# Logistic Regression 
from sklearn.linear_model import LogisticRegre ssion

LogReg = LogisticRegression(random_state $=2$ )

LogReg.fit(Xtrain, Ytrain)

\section{E. Random Forest (RF):}

Random Forest is a ML algorithm. At training situation multitude decision trees are made and the output will be divided based on number of classes i.e., classification, prediction of class i.e., regression. The number of trees is proportional to accuracy in prediction. The dataset includes factors like rainfall, perception, temperature and production. These factors in dataset are used for training. Only two-third of the dataset is considered. Remaining dataset is used for experimental basis. The algorithm random forest has 3 parameters like: $n$ tree which describes the $n$ number of trees which need to grow, m try - mentions how many variables need to be taken at a node split. Node size - In terminal nodes it suggest us the number of observation need to take [1].

We have applied Random Forest (RF) in our model as:

(i) Importing library

RandomForestClassifier from sklearn.ensemble Class

(ii) Now we create RF classifier object

(iii) In the last we fit our data

\# Random Forest
from sklearn.ensemble import RandomForestCl
assifier
RF = RandomForestClassifier(n_estimators=20,
random_state=0)
RF.fit(Xtrain,Ytrain)

eXtreme Gradient Boosting (XGBoost) is a adaptable and improved rendition of the gradient boosting algorithm designed for viability, computational speed and model performance. XGBoost is well known to provide better solutions than other machine learning algorithms. It is an open-source library and a part of the Distributed Machine Learning Community. XGBoost provides a parallel tree boosting (also known as GBDT, GBM) that solve many data science problems in a fast and accurate way.

We have applied XGBoost in our model as:

(i) Importing library xgboost

(ii) Now we create XB classifier object

(iii) In the last we fit our data

\section{\# XGBoost}

import xgboost as $\mathrm{xgb}$

$\mathrm{XB}=\mathrm{xgb} . \mathrm{XGBClassifier()}$

XB.fit(Xtrain, Ytrain)

\section{Experimental Result}

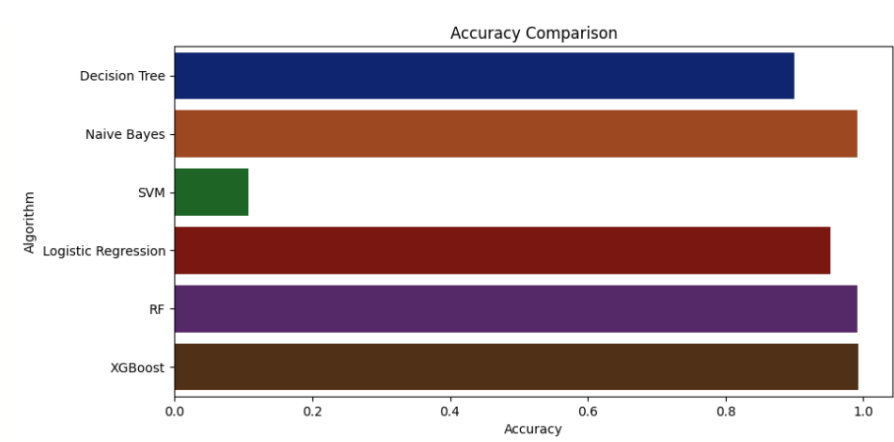

Fig 2 : Accuracy Comparison

Decision Tree $-\rightarrow 0.9$

Naive Bayes --> 0.990909090909091

SVM - 0.10681818181818181

Logistic Regression --> 0.9522727272727273

RF - $>0.990909090909091$

XGBoost - $\rightarrow 0.9931818181818182$

Fig 3: Machine Learning vice Accuracy Result

\section{F. XGBoost:}




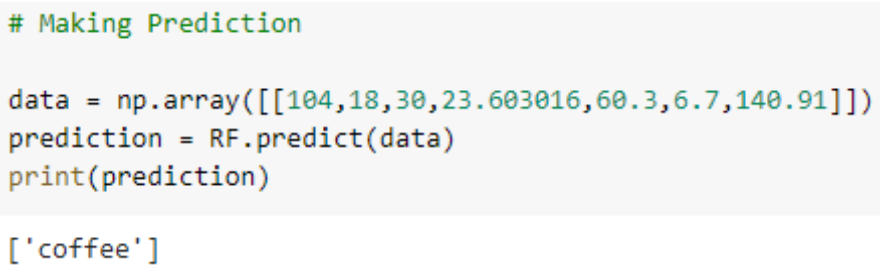

Fig 4 : Prediction Snapshot

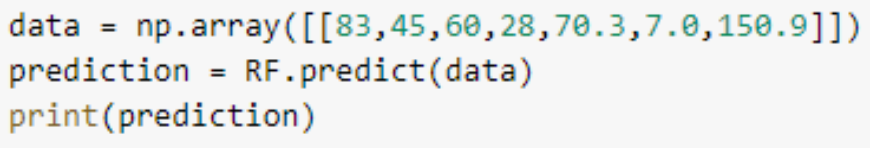

Fig 5 : Prediction Snapshot

\section{Result Analysis}

\begin{tabular}{|c|c|}
\hline Algorithm & Accuracy \\
\hline Decision Tree (DT) & $90 \%$ \\
\hline Naïve Bayes (NB) & $99 \%$ \\
\hline $\begin{array}{c}\text { Support Vector } \\
\text { Machine (SVM) }\end{array}$ & $10.68 \%$ \\
\hline $\begin{array}{c}\text { Logistic Regression } \\
\text { (LR) }\end{array}$ & $95.22 \%$ \\
\hline Random Forest (RF) & $99 \%$ \\
\hline XGBoost & $99.31 \%$ \\
\hline
\end{tabular}

Table 1 : Algorithm vice Accuracy Result in Percentage

\section{CONCLUSION}

In this paper, we have effectively proposed and implemented an intelligent crop recommendation system, which can be easily used by farmers all over India. This system would help the farmers in making an informed decision about which crop to grow depending on some parameters like Nitrogen, Phosphorous, Pottasium, PH Value, Humidity, Temperature, and Rainfall. By using this research we can increase productivity of the country and produce profit out of such a technique. In this manner the farmer's can plant the right crop increasing his yield and also increasing the overall profitability of the country. This investigation has expressed the recommendation of various crops of India using different machine learning algorithms like Decision Tree, Naïve Bayes, Support Vector Machine, Logistic Regression, Random Forest and XGBoost. The Analysis has been performed on these six types of machine learning algorithms and out of these six algorithms XGBoost achieved best accuracy result.

\section{Future Work}

The system can be enhanced further to add following functionality:

1. The main future work's aim is to improved dataset with larger number of attributes.

2. We need to build a model, which can classify between healthy and diseased crop leaves and also if the crop has any disease, predict which disease is it.

3. To build website and mobile app for easy to use.

\section{REFERENCES}

[1]. Kumar, Y. Jeevan Nagendra, V. Spandana, V. S. Vaishnavi, K. Neha, and V. G. R. R. Devi. "Supervised Machine learning Approach for Crop Yield Prediction in Agriculture Sector." In 2020 5th International Conference on Communication and Electronics Systems (ICCES), pp. 736-741. IEEE, 2020.

[2]. Nigam, Aruvansh, Saksham Garg, Archit Agrawal, and Parul Agrawal. "Crop yield prediction using machine learning algorithms." In 2019 Fifth International Conference on Image Information 
Processing (ICIIP), pp. 125-130. IEEE, 2019.

[3]. Medar, Ramesh, Vijay S. Rajpurohit, and Shweta Shweta. "Crop yield prediction using machine learning techniques." In 2019 IEEE 5th International Conference for Convergence in Technology (I2CT), pp. 1-5. IEEE, 2019.

[4]. Jain, Sonal, and Dharavath Ramesh. "Machine Learning convergence for weather based crop selection." In 2020 IEEE International Students' Conference on Electrical, Electronics and Computer Science (SCEECS), pp. 1-6. IEEE, 2020.

[5]. Gandge, Yogesh. "A study on various data mining techniques for crop yield prediction." In 2017 International Conference on Electrical, Electronics, Communication, Computer, and Optimization Techniques (ICEECCOT), pp. 420-423. IEEE, 2017.

[6]. Suresh, A., P. Ganesh Kumar, and M. Ramalatha. "Prediction of major crop yields of Tamilnadu using K-means and Modified KNN." In 2018 3rd International Conference on Communication and Electronics Systems (ICCES), pp. 88-93. IEEE, 2018.

[7]. Kamatchi, S. Bangaru, and R. Parvathi. "Improvement of Crop Production Using Recommender System by Weather Forecasts." Procedia Computer Science 165 (2019): 724-732.

[8]. Bondre, Devdatta A., and Santosh Mahagaonkar. "Prediction of Crop Yield and Fertilizer Recommendation Using Machine Learning Algorithms." International Journal of Engineering Applied Sciences and Technology 4, no. 5 (2019): 371-376.

[9]. Suresh, G., A. Senthil Kumar, S. Lekashri, and R. Manikandan. "Efficient Crop Yield
Recommendation System Using Machine Learning For Digital Farming." International Journal of Modern Agriculture 10, no. 1 (2021): 906-914.

[10].Reddy, D. Anantha, Bhagyashri Dadore, and Aarti Watekar. "Crop recommendation system to maximize crop yield in ramtek region using machine learning." International Journal of Scientific Research in Science and Technology 6, no. 1 (2019): 485-489.

[11] .Pudumalar, S., E. Ramanujam, R. Harine Rajashree, C. Kavya, T. Kiruthika, and J. Nisha. "Crop recommendation system for precision agriculture." In 2016 Eighth International Conference on Advanced Computing (ICoAC), pp. 32-36. IEEE, 2017.

[12].Garanayak, Mamata, Goutam Sahu, Sachi Nandan Mohanty, and Alok Kumar Jagadev. "Agricultural Recommendation System for Crops Using Different Machine Learning Regression Methods." International Journal of Agricultural and Environmental Information Systems (IJAEIS) 12, no. 1 (2021): 1-20.

[13] .Jejurkar Siddhi, S., S. Bhosale Meghna, and D. N. Wavhal. "Crop Predication and Diseases Detection Using Machine Learning." (2021).

[14] .Rajak, Rohit Kumar, Ankit Pawar, Mitalee Pendke, Pooja Shinde, Suresh Rathod, and Avinash Devare. "Crop recommendation system to maximize crop yield using machine learning technique." International Research Journal of Engineering and Technology 4, no. 12 (2017): 950-953.

[15].Doshi, Zeel, Subhash Nadkarni, Rashi Agrawal, and Neepa Shah. "AgroConsultant: Intelligent Crop Recommendation System Using Machine Learning Algorithms." In 2018 Fourth International Conference on Computing 
Communication Control and Automation (ICCUBEA), pp. 1-6. IEEE, 2018.

[16] .Mahule, Ankit Arun, and A. J. Agrawal. "Hybrid Method for Improving Accuracy of Crop-Type Detection using Machine Learning." International Journal 9, no. 2 (2020).

[17] .Akshatha, K. R., and K. S. Shreedhara. "Implementation of machine learning algorithms for crop recommendation using precision agriculture." International Journal of Research in Engineering, Science and Management (IJRESM) 1, no. 6 (2018): 58-60.

[18] .Dighe, Deepti, Harshada Joshi, Aishwarya Katkar, Sneha Patil, and Shrikant Kokate. "Survey of Crop Recommendation Systems." (2018).

[19] .Jaiswal, Sapna, Tejaswi Kharade, Nikita Kotambe, and Shilpa Shinde. "Collaborative Recommendation System For Agriculture Sector." In ITM Web of Conferences, vol. 32. EDP Sciences, 2020.

[20] .Ghadge, Rushika, Juilee Kulkarni, Pooja More, Sachee Nene, and R. L. Priya. "Prediction of crop yield using machine learning." Int. Res. J. Eng. Technol.(IRJET) 5 (2018).

[21] .Kulkarni, Nidhi H., G. N. Srinivasan, B. M. Sagar, and N. K. Cauvery. "Improving Crop Productivity Through A Crop Recommendation System Using Ensembling Technique." In 2018 3rd International Conference on Computational Systems and Information Technology for Sustainable Solutions (CSITSS), pp. 114-119. IEEE, 2018.

[22].Kumar, Avinash, Sobhangi Sarkar, and Chittaranjan Pradhan. "Recommendation system for crop identification and pest control technique in agriculture." In 2019 International

Conference
Communication and Signal Processing (ICCSP), pp. 0185-0189. IEEE, 2019.

\section{Cite this article as :}

Dhruvi Gosai, Chintal Raval, Rikin Nayak, Hardik Jayswal, Axat Patel, "Crop Recommendation System using Machine Learning", International Journal of Scientific Research in Computer Science, Engineering and Information Technology (IJSRCSEIT), ISSN : 2456-3307, Volume 7 Issue 3, pp. 558-569, May-June 2021. Available at

doi : https://doi.org/10.32628/CSEIT2173129 Journal

URL : https://ijsrcseit.com/CSEIT2173129 